\title{
Artikel
}

\section{De stand van de stelselherziening: een beslissend jaar}

\author{
Mr. H.W. (Wilco) de Vos*
}

\section{Inleiding}

Het is de bedoeling dat dit jaar de regelgeving van het nieuwe stelsel zal worden afgerond. Inmiddels heeft het parlement vier wetsvoorstellen en de bijbehorende ontwerp-AMvB's behandeld. De parlementaire behandeling is daarmee nog niet afgerond. Er volgt nog de Eerste Kamerbehandeling van de aanvullingswetgeving voor natuur en enkele andere relevante wetsvoorstellen. Een volgende stap is de parlementaire besluitvorming over de datum van inwerkingtreding. ${ }^{1}$

De afgelopen periode is gebleken dat de Eerste Kamer bij de behandeling van de diverse wetgevingsproducten niet over één nacht ijs gaat. De senaat combineert de behandeling van de wetsvoorstellen met de voorhang van de bijbehorende ontwerpbesluiten. Daarbij is sprake van een uitgebreide voorbereiding. Zo heeft de Eerste Kamer bij de invoeringswetgeving diverse technische briefings, twee deskundigenbijeenkomsten en drie schriftelijke vragenrondes gehouden. Ook de plenaire behandeling was zeer uitgebreid en omvatte diverse onderwerpen die op het hele stelsel betrekking hadden. In feite was er sprake van een 'tweede lezing' van de

* Mr. H.W. de Vos is werkzaam bij de directie Constitutionele Zaken en Wetgeving van het Ministerie van Binnenlandse Zaken en Koninkrijksrelaties en is als juridisch projectleider betrokken bij de totstandkoming van de nieuwe omgevingswetgeving. Het artikel is op persoonlijke titel geschreven.

1. Inmiddels is duidelijk geworden dat de Omgevingswet niet per 1 januari 2021 in werking zal treden. Zie hiervoor de brief van de Minister voor Milieu en Wonen: Zie www.tweedekamer.nl/kamerstukken/ brieven_regering/detail id $=2020205972 \&$ did=2020D12510. De tekst van dit artikel is hier alleen op onderdelen op aangepast.
Omgevingswet. Op 11 februari heeft de Eerste Kamer het wetsvoorstel voor de Invoeringswet met een ruime meerderheid aangenomen. ${ }^{2}$ De parlementaire steun voor het nieuwe stelsel is daarmee nog eens bevestigd.

Ook de voorbereiding van de behandeling van de aanvullingswetgeving is in meerdere schriftelijke rondes verlopen. De aanvullingswetsvoorstellen voor geluid en bodem zijn, na een uitgebreide plenaire behandeling, op 18 februari door de Eerste Kamer aangenomen. ${ }^{3}$ Het aanvullingswetsvoorstel grondeigendom is op 10 maart aangenomen. ${ }^{4}$ De aanvullingswetgeving voor natuur zal naar verwachting in april plenair worden behandeld. Inmiddels heeft de Tweede Kamer de voorhangprocedure afgerond van de ontwerpen van het Invoeringsbesluit en de anvullingsbesluiten. De ontwerpen van de Aanvullingsbesluiten geluid, bodem en grondeigendom zijn inmiddels voor advies voorgelegd an de Afdeling advisering van de Raad van State. Het ontwerp van het Aanvullingsbesluit natuur volgt als dat door de Eerste Kamer is behandeld.

Ook op regelingsniveau is er voortgang geboekt. Eind vorig jaar is de Omgevingsregeling vastgesteld en gepubliceerd. Vervolgens zijn de ontwerpen van de Invoeringsregeling en de Aanvullingsregelingen grondeigen-

2. 53 stemmen voor (VVD, CDA, D66, PvdA met uitzondering van de leden Koole en Sent, FVD, PVV, ChristenUnie, 50PLUS en SGP) en 19 stemmen tegen (SP, PvdD, GroenLinks, de PvdA-leden Koole en Sent en Fractie-Otten).

3. Voor beide wetsvoorstellen heeft - net als in de Tweede Kamer - ruim driekwart van de Kamerleden voorgestemd: 57 stemmen voor (VVD, FVD, CDA, D66, PvdA, PVV, ChristenUnie, 50PLUS en SGP) en 17 stemmen tegen (GroenLinks, SP, PvdD en Fractie-Otten). De OSF-fractie was afwezig.

4. 53 stemmen voor: CDA, D66, PvdA, ChristenUnie, SGP, OSF, FVD VVD en 50PLUS, en 22 stemmen tegen: PVV, GroenLinks, SP, PvdD en Fractie-Otten. 
dom, geluid en bodem in consultatie gegaan. Binnenkort start de consultatie van het ontwerp van de Aanvullingsregeling natuur.

De afgelopen maanden is het stelsel weer verder ingevuld. Gezien de belangrijke stappen die de ontwerpbesluiten en ontwerpregelingen nog moeten zetten, is het echter nog te vroeg om van een afrondende fase te kunnen spreken. Ook volgt nog de besluitvorming over de inwerkingtreding. Bij de diverse behandelingen is gebleken dat het parlement kritisch weegt of de uitvoeringspraktijk voldoende is voorbereid op de invoering van het nieuwe stelsel en of het Digitaal Stelsel Omgevingswet (DSO) tijdig gereed zal zijn. Deze elementen zullen nader aan de orde komen bij de voorhang van het inwerkingtredings-KB van de Omgevingswet.

In deze aflevering volgt, zoals gebruikelijk, een korte terugblik op de afgelopen periode en een vooruitblik op dit cruciale jaar voor de stelselherziening. Daarbij zal ook worden ingegaan op enkele andere ontwikkelingen in de wet- en regelgeving die van belang zijn voor het stelsel van de Omgevingswet.

\section{Voortgangsbrief en eindadvies adviescommissie}

\subsection{Het proces richting inwerkingtreding}

Eind november heeft de Minister voor Milieu en Wonen $^{5}$ - in afstemming met de VNG, het IPO en de Unie van Waterschappen - een voortgangsbrief ${ }^{6}$ aan het parlement gestuurd. Daarin is de stand van zaken van de stelselherziening geschetst op het gebied van wetgeving, implementatie en de ontwikkeling van het DSO op weg naar de invoering van het stelsel. Deze brief ging uit van de beoogde inwerkingtreding van de Omgevingswet op 1 januari 2021.

De vaste Tweede Kamercommissie voor Binnenlandse Zaken heeft vervolgens een rondetafelgesprek georganiseerd, waarvoor vertegenwoordigers van diverse organisaties waren uitgenodigd. Daaruit bleek steun, in het bijzonder van de decentrale overheden, voor het tot nu toe gevolgde proces van de stelselherziening. ${ }^{7}$ Dat gold ook, onder het uitdrukkelijke voorbehoud dat er geen kink in de kabel mag komen, voor de ontwikkeling van het DSO. Met de opgeleverde versie van de landelijke voorziening kan vanaf begin dit jaar in de praktijk worden geoefend. Verder kan een start worden gemaakt met het aansluiten van de overheden op deze voorziening en het 'vullen' van het DSO. De vorderingen daar- van zullen medebepalend zijn of de voorgenomen datum van inwerkingtreding wordt gehaald.

Tijdens het rondetafelgesprek kwamen ook andere onderwerpen aan de orde. Zo plaatste de Commissie voor de milieueffectrapportage enkele kanttekeningen bij de afname van verplichte milieueffectrapportages voor bepaalde projecten en de toepassing van de planmer bij onder meer omgevingsvisies. Ook pleitte de commissie voor een nieuwe naam voor milieueffectrapportage: omgevingseffectrapportage. Daarnaast was er een kritisch geluid vanuit natuur- en milieuorganisaties, die onder meer aandacht vroegen voor diverse waarborgen, waaronder een gelijkwaardig beschermingsniveau, en erop aandrongen om de tijd te nemen voor een zorgvuldig vervolg van de stelselherziening. De verschillende geluiden klonken door in het algemeen overleg (AO) dat op 15 januari door de Tweede Kamer werd gehouden. ${ }^{8}$ Daarin was er ook aandacht voor enkele publicaties in de pers over de stelselherziening, waaronder een interview van de Nationale ombudsman, waar de minister op verzoek van de Kamer schriftelijk op heeft gereageerd. ${ }^{9}$ Naar aanleiding van het $\mathrm{AO}$ is een motie aangenomen waarin de Kamer de regering oproept om een voorlichtingscampagne te starten rondom de invoering van de Omgevingswet. Daarin zal ook aandacht zijn voor de positie van burgers ten opzichte van nieuwe ruimtelijke projecten. ${ }^{10}$

Bij brief van 1 april 2020 heeft de Minister voor Milieu en Wonen aan het parlement gemeld dat de Omgevingswet niet per 1 januari 2021 in werking zal treden. Voor een zorgvuldige invoering van de stelselherziening is meer tijd nodig. In overleg met de bestuurlijke partners wordt bekeken welke nieuwe datum wordt beoogd. In de brief is aangegeven hoe het parlement zal worden geïnformeerd over de voortgang. Bij de voorhang van het ontwerp van het inwerkingtredings-KB voor de Omgevingswet zal vervolgens de balans worden opgemakkt. De minister heeft benadrukt dat het ontwerp van het koninklijk besluit (KB) alleen zal worden voorgehangen 'als ik in overleg met de bestuurlijke partners beoordeel dat dit verantwoord is'. Dat zal aan de hand van de volgende elementen worden beoordeeld: de 'mate van stabiliteit van de wetgeving, de voortgang van de implementatie op de minimale vereisten bij de bevoegde gezagen en de voortgang op het DSO' ${ }^{11}$ Vervolgens kan in het parlement daarover het debat worden gevoerd. In het voorgestelde art. 23.10, tweede lid, van de Omgevingswet ${ }^{12}$ is bepaald dat het ontwerp van het $\mathrm{KB}$ niet ter bekrachtiging aan de Koning zal worden voorgelegd als een van beide Kamers zich daarmee niet kan verenigen.
5. In verband met ziekte van minister Ollongren is de verantwoordelijkheid voor wonen, ruimtelijke ordening en de Omgevingswet tijdelijk belegd bij de Minister voor Milieu en Wonen (Van Veldhoven). Zie het Besluit van 1 november 2019, nr. 2019002307 (Stcrt. 2019, 61106).

6. Kamerstukken II 2019/20, 33 118, nr. 123.

7. De inbreng van deze partijen is ook opgenomen in zogenoemde position papers: www.tweedekamer.nl/debat_en_vergadering/ commissievergaderingen/details?id=2019A05313.
8. Het ongecorrigeerde verslag is te vinden op: www.tweedekamer.nl/ kamerstukken/detail?id=2020D01774\&did=2020D01774.

9. Kamerstukken I 2019/20, 34 986, U.

10. Kamerstukken II 2019/20, 33 118, nr. 136.

11. Kamerstukken II 2019/20, 33 118, nr. 123, p. 1-2

12. Zie art. 1.1, onder JNa, van het voorstel voor de Invoeringswet Omgevingswet. 


\subsection{Eindadvies Integrale onafhankelijke adviescommissie Omgevingswet}

Bij de brief van 29 november 2019 was ook gevoegd het rapport van de Integrale onafhankelijke adviescommissie Omgevingswet: Recht doen aan de Omgeving (swet $)^{13} \mathrm{De}$ adviescommissie heeft de afgelopen jaren over diverse onderdelen van het stelsel advies uitgebracht. Het nu uitgebrachte eindadvies gaat over de samenhang, werking en toekomst van het stelsel. De commissie geeft in haar advies een positief oordeel over het juridische bouwwerk:

'De commissie concludeert dat het juridisch bouwwerk goed in elkaar zit. Kijkend naar het stelsel als geheel vanuit juridisch perspectief vindt de commissie dat de wetgever consequent de doelen van de wet centraal heeft gesteld bij het opstellen van de delen van het stelsel alsook bij het ontwerpen van de kerninstrumenten. De commissie vindt het sterk dat de beleidscyclus centraal is gesteld als leidend principe. De commissie is van oordeel dat het juridische bouwwerk systematisch stevig in elkaar zit. Dit wettelijk stelsel is inzichtelijker en gebruiksvriendelijker voor de gebruiker van het recht dan de huidige lappendeken van omgevingsregels in ongeveer honderd wetten, AMvB's en ministeriële regelingen. ${ }^{14}$

Daarnaast beschrijft de commissie wat er nodig is voor een goede invoering en het werken met het nieuwe stelsel. De commissie doet diverse aanbevelingen om de potentie van het nieuwe stelsel ten volle te benutten. Daarbij benadrukt de commissie onder meer de mogelijkheid om de instrumenten te benutten voor 'waardecreatie', zowel bij het beschermen als bij het benutten van de fysieke leefomgeving. ${ }^{15}$ Verder onderstreept de commissie dat het van belang is dat het stelsel ook na inwerkingtreding 'op orde' blijft. ${ }^{16} \mathrm{Ze}$ doet enkele aanbevelingen die erop zijn gericht de samenhang binnen het stelsel te bewaren. Zo beveelt de commissie aan om de doelen en uitgangspunten van de stelselherziening te blijven hanteren bij de verdere uitbreiding en anpassing van het stelsel.

Op verzoek van de Kamers heeft de voorzitter van de commissie eind vorig jaar een bijdrage geleverd an de deskundigenbijeenkomst in de Eerste Kamer en het rondetafelgesprek in de Tweede Kamer. Met het eindadvies van de commissie komt er een einde aan een periode van acht jaar ${ }^{17}$ waarin externe adviesgroepen hebben geadviseerd over de bouw van het nieuwe stelsel. De adviezen van de integrale adviescommissie zijn de afgelopen jaren, vergezeld van een reactie van de betrokken bewindspersonen, aan het parlement aangeboden.

13. Kamerstukken II 2019/20, 33 118, nr. 123, bijlage 1.

14. Kamerstukken II 2019/20, 33 118, nr. 123, bijlage 1, p. 4.

15. Kamerstukken II 2019/20, 33 118, nr. 123, bijlage 1, p. 9 en 10.

16. Kamerstukken II 2019/20, 33 118, nr. 123, bijlage 1, p. 15.

17. In 2011 zijn er voor de stelselherziening van het omgevingsrecht vijf adviesgroepen ingesteld. Deze zijn in 2016 opgegaan in één integrale adviescommissie Omgevingswet.
In het adviesrapport beveelt de commissie aan om voor de toekomst een externe commissie ${ }^{18}$ of commissaris te benoemen met een onafhankelijke positie en gezag op het terrein van de fysieke leefomgeving. Dit om verrommeling van het systeem te voorkomen en de kwaliteit van nieuwe toevoegingen te bewaken. De commissie refereert aan de borging en ontwikkeling van het stelsel van de Algemene wet bestuursrecht (Awb) de afgelopen jaren. De minister heeft in de brief aangegeven dit voorstel met haar collega's in het kabinet en de bestuurlijke partners te gaan bespreken. ${ }^{19}$

\section{Voortgang van de regelgeving}

Een belangrijke voorwaarde voor inwerkingtreding van het stelsel is dat de regelgeving tijdig is afgerond. Hieronder wordt ingegaan op de stand van de regelgeving.

\subsection{Ministeriële regelingen: vaststelling Omgevingsregeling en consultatie \\ Invoeringsregeling en aanvullingsregelingen}

Op 22 november 2019 is de Omgevingsregeling ${ }^{20}$ gepubliceerd, waarmee - na de eerdere publicatie van de Omgevingswet en de vier AMvB's - het hoofdspoor van de Omgevingswet is afgerond. De Omgevingsregeling is de eerste regeling van het Rijk die volgens de nieuwe digitale standaard (STOP-TPOD AMvB-MR) ${ }^{21}$ is gepubliceerd, zodat die via het DSO kan worden ontsloten.

Een tweede novum is dat wijzigingen van de Omgevingsregeling niet langer via wijzigingsopdrachten ${ }^{22}$ zullen worden vormgegeven, maar door middel van revisies (in renvooi) in de tekst van de Omgevingsregeling worden weergegeven. Dit is terug te zien in de voorgestelde wijzigingen en aanvullingen in de consultatieversies van de Invoeringsregeling ${ }^{23}$ en de aanvullingsregelingen, bijvoorbeeld de Aanvullingsregeling grondeigendom. ${ }^{24}$ Deze weergave maakt het eenvoudiger om de betekenis en het effect van de voorgestelde wijzigingen te doorgronden. Deze nieuwe vorm van wijzigingsregelgeving zal ook in de Aanwijzingen voor de regelgeving worden opgenomen.

Met de invoeringsregeling en de aanvullingsregelingen bodem en grondeigendom worden in totaal 69 ministeriële regelingen ingetrokken en 86 regelingen gewijzigd. Binnenkort zullen de ontwerpen van de aanvullingsregelingen voor geluid en natuur voor consultatie op

18. De commissie heeft blijkens het rapport nadrukkelijk niet zichzelf voor ogen bij deze commissie.

19. Kamerstukken II 2019/20, 33 118, nr. 123, p. 12.

20. Stcrt. 2019, 56288. Digitaal: https://zoek.officielebekendmakingen.nl/ stcrt-2019-56288.

21. Standaard officiële overheidspublicaties (STOP)-Toepassingsprofiel omgevingsdocumenten (TPOD) AMvB-MR.

22. Bijv. 'onderdeel $x$ wordt vervangen door onderdeel $y$ ', 'artikel $z$ komt te luiden:', enz.

23. Zie www.internetconsultatie.nl/invoeringsregelingomgevingswet.

24. Zie www.internetconsultatie.nl/aanvullingsregelinggrondeigendom. 
internet worden gepubliceerd. Dan is op regelingsniveau het beeld compleet.

\subsection{AMvB's: voorhang van de ontwerpen van het} Invoeringsbesluit en de aanvullingsbesluiten De ontwerpen van het Invoeringsbesluit en de vier aanvullingsbesluiten zijn bij het parlement voorgehangen. Deze ontwerpbesluiten bevatten wijzigingen en aanvullingen van de vier AMvB's op grond van de Omgevingswet: het Besluit kwaliteit leefomgeving (Bkl), het Besluit activiteiten leefomgeving (Bal), het Besluit bouwwerken leefomgeving $(\mathrm{Bbl})$ en het Omgevingsbesluit (Ob). Er zijn geconsolideerde versies van die AMvB's beschikbaar waarin de voorgestelde wijzigingen en aanvullingen zijn verwerkt. ${ }^{25}$ Die versies geven een goed beeld van hoe de vier AMvB's er op het moment van inwerkingtreding uit komen te zien. Daarnaast worden met het Invoeringsbesluit en de aanvullingsbesluiten 45 AMvB's ingetrokken en 52 AMvB's gewijzigd.

$\mathrm{Na}$ schriftelijke vragenrondes (en in enkele gevallen een algemeen overleg) in commissieverband heeft de Tweede Kamer plenair de behandeling afgerond van de voorgehangen ontwerpen van het Invoeringsbesluit en de Aanvullingsbesluiten bodem, geluid, grondeigendom en natuur. ${ }^{26}$ Daarbij is een aantal moties aangenomen: bij het Invoeringsbesluit over het beschermen van de vrije windvang van historische molens ${ }^{27}$ en bij het Aanvullingsbesluit bodem over de omgang met bodemverontreiniging nabij drinkwatervoorzieningen ${ }^{28}$ en over integrale visies op grondwaterbeheer onder regie van de provincies. $^{29}$ Bij het aanvullingsbesluit natuur zijn moties aangenomen over de toegankelijkheid van natuurinformatie in het DSO en over het beperken van overlast door steenmarters. ${ }^{30}$ Deze zullen in de ontwerp-AMvB's of de nota van toelichting worden verwerkt.

De Eerste Kamer ${ }^{31}$ combineert de behandelingen van de ontwerpbesluiten met het bijbehorende wetsvoorstel. Deze lopen daardoor gelijk op. Een verschil is dat, na afronding van de behandeling door de Eerste Kamer, de ontwerpbesluiten nog voor advies aan de Afdeling advisering van de Raad van State zullen worden voorgelegd. Voor de wetsvoorstellen is dat al in een eerder stadium van de wetgevingsprocedure gebeurd. geconsolideerde-versies-omgevingswet-en-amvb\%E2\%80\%99sbeschikbaar.

26. Via een VSO (= verslag schriftelijk overleg) of VAO (= verslag algemeen overleg) op: 12 december (Aanvullingsbesluit bodem), 18 december (Invoeringsbesluit), 4 februari (Aanvullingsbesluiten geluid en grondeigendom) en 13 februari (Aanvullingsbesluit natuur).

27. Kamerstukken II 2019/20, 34 985, nr. 53

28. Kamerstukken II 2019/20, 34 864, nr. 23

29. Kamerstukken II 2019/20, 34 864, nr. 25.

30. Kamerstukken II 2019/20, 34 985, nrs. 56 en 60.

31. Het voortouw ligt bij de vaste commissie voor Infrastructuur, Waterstaat en Omgeving (commissie IWO). De behandeling van de voorstellen voor de Aanvullingswetten natuur en grondeigendom wordt samen met de vaste commissie voor EZK/LNV voorbereid.

\subsection{Wetten: wetsvoorstellen in behandeling bij Eerste Kamer}

De Tweede Kamer heeft op 17 oktober 2019 ingestemd met het voorstel voor de Aanvullingswet grondeigendom Omgevingswet. ${ }^{32}$ Daarmee waren het voorstel voor de Invoeringswet én alle voorstellen voor de aanvullingswetten gelijktijdig bij de Eerste Kamer aanhangig. De Eerste Kamer heeft voor deze voorstellen een (nader) voorlopig verslag of verslag uitgebracht, dat is gevolgd door een (nadere) memorie van antwoord, respectievelijk een nota naar aanleiding van het verslag. ${ }^{33}$ De Eerste Kamer heeft ervoor gekozen om eerst het voorstel voor de Invoeringswet plenair te behandelen. Daarop wordt in de volgende paragraaf ingegaan. De voorstellen voor de Aanvullingswetten geluid en bodem en de bijbehorende ontwerpbesluiten zijn op 11 februari plenair behandeld. ${ }^{34}$ De wetsvoorstellen zijn op 18 februari door de Eerste Kamer aanvaard. Bij het voorstel voor de Aanvullingswet geluid is een motie aangenomen over provinciale bevoegdheden bij regionale industrieterreinen. ${ }^{35}$ Die roept de regering op om de vaststelling en het beheer van geluidproductieplafonds voor industrieterreinen van provinciaal belang, zeker die terreinen waarbij de gemeentegrenzen worden overschreden, bij de provincie onder te brengen. Het voorstel voor de Aanvullingswet grondeigendom is op 10 maart aanvaard. Bij de behandeling van dat wetsvoorstel heeft de Eerste Kamer geen moties aangenomen.

De plenaire behandeling van de aanvullingswetgeving over natuur zal naar verwachting in april plaatsvinden.

\section{Eerste Kamerbehandeling Invoeringswet en -besluit}

Mede door de wisseling van de samenstelling van de Eerste Kamer in juni vorig jaar kende de behandeling van de invoeringsregelgeving een uitgebreide voorbereidingsprocedure. De eerste inhoudelijke schriftelijke bijdrage van de Kamer in de nieuwe samenstelling was het nader voorlopig verslag in november. Dit is in december gevolgd door een nadere memorie van antwoord. ${ }^{36}$ Vervolgens heeft de Eerste Kamer een verslag uitgebracht, dat begin januari is gevolgd door een nota naar

32. Handelingen II 2019/20, nr. 15, item 5, p. 1.

33. Aanvullingswet geluid: Kamerstukken I 2019/20, 35 054, D, E en F. Aanvullingswet bodem: Kamerstukken I 2019/20, 34 864, F t/m I. Aanvullingswet natuur: Kamerstukken I 2019/20, 34 985, E en F. Aanvullingswet grondeigendom: Kamerstukken I 2019/20, 35 133, D, E en F.

34. De inhoudelijke bespreking van die behandelingen en de behandeling van de Aanvullingswet grondeigendom is niet meer in deze aflevering meegenomen. Een impressie van het debat is te vinden op: www.eerstekamer.nl/nieuws/20200211/debat_aanvullingswet_geluid, www.eerstekamer.nl/nieuws/20200211/debat_aanvullingswet_bodem en www.eerstekamer.nl/nieuws/20200303/debat_aanvullingswet_ grondeigendom.

35. Kamerstukken I 2019/20, 35 054, I.

36. Kamerstukken I 2019/20, 34 986, R en S. 
aanleiding van het verslag. ${ }^{37}$ Daarmee was de voorbereidende schriftelijke behandeling van het wetsvoorstel afgerond. Er viel niettemin nog veel te bespreken. Vanwege de ruime spreektijden begon de plenaire behandeling al op maandagavond 27 januari en vulde op 28 januari ook de reguliere vergaderdag tot laat in de avond. Op 11 februari vond er nog een vierde termijn van het debat plaats. Aanleiding daarvoor waren berichten in de media over een rapport van het Inspectiebureau voor Leefomgeving en Transport over de borging van nationale ruimtelijke belangen in de ruimtelijke ordening. ${ }^{38}$ Uit dat rapport zou blijken dat gemeenten en provincies zich in de periode 2012 tot 2017 niet aan de afspraken en landelijke normen voor ruimtelijke ordening hebben gehouden. De minister heeft hierover twee brieven aan de Kamer gezonden. ${ }^{39}$ Onderwerp van bespreking in de vierde termijn was de verhouding van de in het rapport gesignaleerde uitvoerings- en handhavingsproblemen tot het nieuwe stelsel. Dit leidde onder meer tot de toezegging van de minister om een vergelijkbaar onderzoek te laten doen nadat de Omgevingswet in werking is getreden.

Vervolgens is er gestemd over de moties en het wetsvoorstel. Op verzoek van de Partij voor de Dieren (PvdD) is hoofdelijk over het wetsvoorstel gestemd. Daarbij wordt uitgegaan van het aantal aanwezige leden (op dat moment 72 leden). Een hoofdelijke stemming kan ertoe leiden dat binnen een fractie de stemmen verschillen. Dat deed zich voor bij de PvdA-fractie, waarvan vier leden voor en twee leden tegen ${ }^{40}$ hebben gestemd. In totaal hebben 53 Eerste Kamerleden voor en 19 tegen het wetsvoorstel gestemd.

Op de website van de Eerste Kamer is een korte samenvatting van het debat te vinden. ${ }^{41}$ De standpunten van de diverse fracties liepen uiteen van uitgesproken kritisch (de fracties van de PvdD en Otten) tot expliciete ondersteuning van het nieuwe stelsel. De behandeling van het voorstel voor de Invoeringswet is gaandeweg uitgegroeid tot een behandeling van een aantal centrale thema's van het nieuwe stelsel van de Omgevingswet. Hieronder worden drie thema's kort aangestipt. Daarnaast had de Eerste Kamer veel aandacht voor de stand van zaken van de implementatie en de ontwikkeling van het DSO. Die onderwerpen blijven hier buiten beschouwing.

\subsection{Balans beschermen en benutten}

Onder dit thema werden diverse onderwerpen geschaard, zoals de afwegingsruimte voor bestuursorganen en gelijkwaardig beschermingsniveau. Centraal daarbij stond de vraag naar de effecten van de Omge-

37. Kamerstukken I 2019/20, 34 986, V en W.

38. Ministerie hield rapport over falen ruimtelijke ordening tegen, NRC 9 februari 2020

39. Kamerstukken I 2019/20, 33 118, AZ en BA.

40. De redenen lagen volgens de stemverklaring in het verloop van de behandeling op 18 februari.

41. Zie www.eerstekamer.nl/nieuws/20200128/veel_vragen_over invoeringswet. vingswet voor (onderdelen van) de fysieke leefomgeving. Die zullen zich uiteindelijk, binnen de grenzen van de nieuwe regels, in de praktijk voordoen. In het debat was er dan ook veel aandacht voor monitoring en evaluatie. Bij de evaluatie van de wet (art. 23.9 Ow) zal expliciet aandacht worden besteed aan de balans tussen beschermen en benutten. Uit het debat kwam naar voren dat er een onafhankelijke evaluatiecommissie komt. Ook was er voor diverse onderwerpen een oproep om niet te wachten op de wettelijke evaluatietermijn (vijf jaar), maar om jaarlijks te monitoren. Dit gold ook voor de balans tussen beschermen en benutten. De minister heeft hierover diverse toezeggingen gedaan en zal in de komende voortgangsbrief hiervan een overzicht geven. In die brief, die voorafgaand aan de voorhang van het inwerkingtredings-KB wordt gestuurd, zal worden ingegaan op de inrichting van de evaluatiecommissie en de aanpak van de monitoring.

\subsection{Rechtsbescherming}

Tijdens de behandeling gingen diverse vragen over rechtsbescherming. Onder meer de vraag of er sprake is van een gelijkwaardig niveau van rechtsbescherming, en wat de gevolgen zijn voor de rechterlijke macht. Het voert te ver om in het bestek van dit artikel in te gaan op de verschillende aspecten en naar voren gebrachte punten. In de beantwoording heeft de minister onder meer uiteengezet dat voor het beroep bij de rechter grotendeels is aangesloten bij het huidige recht (met uitzondering van de onderdelen van gemeentelijke verordeningen die opgaan in het omgevingsplan, waarvoor een nieuwe beroepsmogelijkheid ontstaat). In de bijlage bij de nota naar aanleiding van het verslag is daarvan een uitgebreid en inzichtelijk overzicht opgenomen. ${ }^{42}$ Voor de rechterlijke macht zal de invoering van het nieuwe stelsel gepaard gaan met nieuwe vragen en daardoor naar verwachting in de transitieperiode tot extra belasting leiden. Hiervoor is in het prijsakkoord met de Raad voor de rechtspraak voor de periode 2020-2022 een voorziening getroffen. Daarnaast zal worden gemonitord wat de eventuele structurele effecten zijn.

\subsection{Participatie}

Net als bij de behandeling in de Tweede Kamer was een belangrijk discussieonderwerp de vraag of, en in hoeverre, er in de wetgeving eisen over de vormgeving van participatie zouden moeten worden vastgelegd. Diverse partijen drongen daarop aan, om de uitvoeringspraktijk houvast te geven en eventueel ook rechterlijke toetsing mogelijk te maken. Andere partijen wezen op het feit dat elk participatieproces maatwerk vereist en waarschuwden voor juridificering. Bij de behandeling werd ook de link gelegd met het ontwerp van het voorstel voor de Wet versterking participatie op decentraal niveau. ${ }^{43}$ Daarin wordt voorgesteld om de inspraakverordening op grond van de Gemeentewet, Waterschapswet en Provinciewet om te vormen tot participatieveror-

42. Kamerstukken I 2019/20, 34 986, S, p. 126-129.

43. Zie www.internetconsultatie.nl/participatieverordening. 
dening. Uiteindelijk is er een motie ${ }^{44}$ aangenomen, waarin de regering wordt opgeroepen om via het Invoeringsbesluit te bevorderen dat gemeenten, provincies en waterschappen al zo spoedig mogelijk participatiebeleid opstellen. De minister heeft aangegeven dat voor diverse instrumenten van de Omgevingswet, zoals omgevingsvisies, omgevingsplannen, waterschaps- en omgevingsverordeningen, een motiveringsplicht zal worden opgenomen, waarmee decentrale overheden moeten aangeven in hoeverre aan het lokaal vastgestelde en gepubliceerde participatiebeleid is voldaan. Dit zal worden opgenomen in het ontwerp van het Invoeringsbesluit, dat voor advies wordt voorgelegd aan de Afdeling advisering van de Raad van State.

\section{Andere ontwikkelingen in de wet- en regelgeving}

Buiten de stelselherziening zijn er ook enkele andere ontwikkelingen die van belang zijn voor het nieuwe stelsel.

\subsection{Andere relevante wetsvoorstellen}

Bij het parlement zijn nog enkele wetsvoorstellen aanhangig die wijzigingen van de Omgevingswet bevatten.

Ten eerste gaat het om het voorstel voor de Wet elektronische publicaties. ${ }^{45}$ Dat wetsvoorstel bevat onder meer regels over de elektronische bekendmaking van regelingen en besluiten. Dit voorstel wijzigt algemene wetten als de Bekendmakingswet en de Awb. Het geeft een nieuwe betekenis aan de begrippen 'kennisgeving' en 'mededeling'. De term 'mededeling' wordt voortaan gebruikt voor de publicatie van een integrale tekst en de term 'kennisgeving' voor de publicatie van de zakelijke inhoud van een tekst onder verwijzing naar een vindplaats elders via elektronische of fysieke terinzagelegging. Ook de relevante bepalingen van de Omgevingswet worden daarmee in lijn gebracht. De Tweede Kamer heeft het voorstel voor de Wet elektronische publicaties in december met algemene stemmen aangenomen. De stand van zaken van de schriftelijke behandeling in de Eerste Kamer is dat de Eerste Kamer een nader voorlopig verslag heeft uitgebracht. ${ }^{46}$

Een tweede voorstel betreft een wijziging van de Awb en enkele andere wetten in verband met het nieuwe omgevingsrecht en nadeelcompensatierecht. ${ }^{47}$ Dat voorstel

44. Kamerstukken I 2019/20, 34 986, AA.

45. Het bij koninklijke boodschap van 6 juni 2019 aangeboden voorstel van wet tot wijziging van de Bekendmakingswet en andere wetten in verband met de elektronische publicatie van algemene bekendmakingen, mededelingen en kennisgevingen (Wet elektronische publicaties) (Kamerstukken 35 218)

46. Kamerstukken I 2019/20, 35 218, D

47. Het bij koninklijke boodschap van 10 juli 2019 aangeboden voorstel van wet tot wijziging van de Algemene wet bestuursrecht en enkele andere wetten in verband met het nieuwe omgevingsrecht en nadeelcompensatierecht (Kamerstukken 35 256). voorziet onder andere in een nieuwe algemene coördinatieregeling in de Awb en vult hoofdstuk 16 (procedures) van de Omgevingswet aan. Daarnaast maakt het wetsvoorstel de inwerkingtreding van de algemene nadeelcompensatieregeling van de Awb mogelijk. Die regeling vormt de basis voor de nadeelcompensatieregeling in de Omgevingswet. Begin dit jaar is een tweede nota van wijziging uitgebracht. Die leidt ertoe dat voor de rechtsmacht van de bestuursrechter inzake nadeelcompensatiebesluiten wordt aangesloten bij de hoofdregel van rechtspraak in twee instanties (beroep bij de rechtbank en hoger beroep bij - normaliter - de Afdeling bestuursrechtspraak van de Raad van State) ${ }^{48}$ Op deze manier wordt een teruggang in rechtsbescherming voorkomen. Het wetsvoorstel is vervolgens door de Tweede Kamer aangemeld voor plenaire behandeling.

Beide wetsvoorstellen hebben een brede betekenis, die verder strekt dan het omgevingsrecht. De voorgestelde wijzigingen van de Omgevingswet zullen tegelijk met het stelsel van de Omgevingswet in werking treden.

\subsection{Andere ontwikkelingen binnen het omgevingsrecht}

De afgelopen maanden waren diverse omgevingsrechtelijke thema's volop in het nieuws. In het bijzonder betrof het de PFAS-norm en de stikstofproblematiek. Deze thema's weerspiegelden de nauwe relatie tussen de kwaliteit van de fysieke leefomgeving en de mogelijkheid om nieuwe activiteiten te verrichten (woningbouw, agrarische activiteiten, aanleg van infrastructuur enzovoort) en de diverse daarbij betrokken belangen.

Op het gebied van wet- en regelgeving heeft dit geleid tot de Spoedwet aanpak stikstof. ${ }^{49}$ Deze wet heeft onder meer de Wet natuurbescherming (Wnb) gewijzigd. Daarin is onder andere de omschrijving van de vergunningplicht voor Natura 2000-activiteiten aangepast en is voorzien in een grondslag voor een regeling voor de registratie van stikstofdepositieruimte. Aangezien de Wnb zal opgaan in het stelsel van de Omgevingswet, zijn in de spoedwet ook vergelijkbare wijzigingen van de Omgevingswet opgenomen. Vervolgens zal ook de uitvoeringsregelgeving een plek binnen het stelsel krijgen.

\section{Vervolg}

De afgelopen maanden hebben beide Kamers een groot aantal activiteiten ontplooid die betrekking hadden op de stelselherziening van het omgevingsrecht. In vrijwel elke procedurevergadering van de betrokken Kamercommissies kwam een onderdeel aan de orde. Dit heeft geleid tot diverse briefwisselingen, schriftelijke vragenrondes, VSO's, AO's, VAO's ${ }^{50}$ en plenaire behandelingen. Beide Kamers hebben deskundigenbijeenkomsten

\footnotetext{
48. Kamerstukken II 2019/20, 35 256, nr. 8, p. 2.

49. Stb. 2019, 517

50. Met het VSO en VAO wordt het overleg plenair afgerond. Tijdens zo'n overleg kunnen moties worden ingediend.
} 
georganiseerd en hebben expliciet aandacht besteed aan adviezen, position papers en uiteenlopende publicaties ${ }^{51}$ die in de diverse media zijn verschenen.

Het verloop van deze parlementaire activiteiten, in het bijzonder het door de Eerste Kamer aanvaarden van de voorstellen voor de Invoeringswet en de Aanvullingswetten bodem, geluid en grondeigendom, laat zien dat de stelselherziening op een brede parlementaire steun kan rekenen. Dat is van belang voor de continuiteit en bestendigheid daarvan. Temeer nu sinds de totstandkoming van de Omgevingswet zowel het kabinet als de Tweede Kamer en de Eerste Kamer van samenstelling zijn veranderd. Voor het langlopende proces van de stelselherziening, dat zich uitstrekt over meerdere kabinetsperiodes, is een breed draagvlak dan ook van groot belang. Een sprekend voorbeeld daarvan is dat minister Van Veldhoven, de huidige stelselverantwoordelijke minister, ten tijde van de behandeling van het wetsvoorstel Omgevingswet als Tweede Kamerlid voor D66 bij dit dossier was betrokken. D66 maakte toen geen deel uit van het kabinet, maar steunde wel het voorstel voor de Omgevingswet.

De voortgang van de totstandkoming van de wet- en regelgeving schept steeds meer duidelijkheid over hoe het stelsel eruit komt te zien. De komende periode kan daarop worden voortgebouwd en kan verder worden gewerkt aan de voorbereiding op de invoering. De beoogde datum van inwerkingtreding is niet langer 1 januari 2021. Niettemin zullen de werkzaamheden aan de regelgeving, implementatie en het DSO onverminderd worden gecontinueerd op weg naar een zorgvuldige invoering. Het bepalen van een nieuwe datum zal afhankelijk zijn van de voortgang daarvan, waarbij ook rekening gehouden zal worden met de gevolgen van de coronamaatregelen. Bij de voorhang van het inwerkingtredings-KB vindt de definitieve afweging plaats over het moment waarop de nieuwe regelgeving in werking treedt. 